\title{
The Possible Role of Epigenetics in Gestational Diabetes: Cause, Consequence, or Both
}

\author{
J. L. Fernández-Morera, ${ }^{1}$ S. Rodríguez-Rodero, ${ }^{2}$ E. Menéndez-Torre, ${ }^{1}$ and M. F. Fraga ${ }^{3}$ \\ ${ }^{1}$ Endocrinology and Nutrition Service, Hospital Universitario Central de Asturias, Av. Julian Clavería s/n, 33006 Oviedo, Spain \\ ${ }^{2}$ Cancer Epigenetics Laboratory, Instituto Universitario de Oncología del Principado de Asturias (IUOPA), Universidad de Oviedo, \\ HUCA, 33006 Oviedo, Spain \\ ${ }^{3}$ Department of Immunology and Oncology, National Center for Biotechnology, CNB-CSIC, Cantoblanco, 28049 Madrid, Spain
}

Correspondence should be addressed to M. F. Fraga,mffraga@cnb.csic.es

Received 23 February 2010; Accepted 22 August 2010

Academic Editor: Julian T. Parer

Copyright ( $\odot 2010$ J. L. Fernández-Morera et al. This is an open access article distributed under the Creative Commons Attribution License, which permits unrestricted use, distribution, and reproduction in any medium, provided the original work is properly cited.

Gestational diabetes mellitus (GDM) is defined as the glucose intolerance that is not present or recognized prior to pregnancy. Several risk factors of GDM depend on environmental factors that are thought to regulate the genome through epigenetic mechanisms. Thus, epigenetic regulation could be involved in the development of GDM. In addition, the adverse intrauterine environment in patients with GDM could also have a negative impact on the establishment of the epigenomes of the offspring.

\section{Gestational Diabetes Mellitus}

Late pregnancy is characterized by moderate peripheral insulin resistance and hyperinsulinemia, both of which are necessary to ensure an appropriate supply of nutrient to the fetus. It is counteracted by the adaptation of the islets of Langerhans to the higher insulin demand. This adaptation is characterized by an increase of insulin biosynthesis, enhanced glucose-stimulated insulin secretion, and an increase of b-cell mass. It is not completely understood why, in some individuals, the b-cell mass and function fail to adapt to the metabolic demands of pregnancy and why blood glucose concentration rises to pathological levels [ 1 , 2 ]. Gestational diabetes mellitus (GDM) is defined as glucose intolerance that was not present or recognized prior to pregnancy and it is diagnosed when the pancreatic function in women is not sufficient to control the diabetogenic environment that pregnancy confers [3]. The diagnosis of GDM also identifies pregnancies at increased risk of perinatal morbidity [4].

The incidence of GDM differs among ethnic populations, with higher rates in African American, Hispanic, American Indian, and Asian women than in white women; values range from $1.4 \%$ to $14 \%$ but overall the condition commonly affects between $2 \%$ and $5 \%$ of pregnant women [5].

The frequency of GDM varies in direct proportion to the prevalence of type II diabetes in populations, and women who develop GDM during pregnancy have a higher risk of developing type 2 diabetes (T2D) later in their lives. These observations are important for relating the two pathological situations and they probably arise from common physiopathological mechanisms [6].

There are two different methods for classifying diabetes in pregnancy. The most recent is the American Diabetes Association (ADA) classification [7] but the White classification is still useful [8] even though it was published in 1949.

1.1. Risk Factors for GDM. Several risk factors are associated with the development of GDM. The most common is obesity (body mass index over 30) diagnosed before pregnancy [9]. Being a member of an ethnic group with a higher rate of type II diabetes (as mentioned above), polycystic ovarian syndrome [10], essential hypertension, or pregnancy-related hypertension [11], strong family history of diabetes in first-degree relatives and a history of GDM in a previous pregnancy are other important risk factors [12]. 
Nevertheless, no risk factors are known in around 50\% of patients with GDM.

There is enough evidence to assert that T2D has a strong genetic component. The concordance of T2D in monozygotic twins is approximately $70 \%$, compared with $20 \%-30 \%$ in dizygotic twins $[13,14]$.

Family studies have prompted the emergence of new perspectives regarding the identification of GDM susceptibility genes. Familial clustering of GDM and T2D have been studied, linking T2D and impaired glucose tolerance in families with GDM [15] and there is evidence of a higher incidence of T2D in mothers of women with GDM [16].

The latest genome-wide studies have identified a number of genetic variants that can explain some of the interindividual discrepancies in diabetes susceptibility $[17,18]$ and different genes have been associated with GDM and T2D [19]. Although classical MHC class II molecules HLA-DR3 and DR4 were not found to be related to GDM [20], recent studies have found genetic evidence from PPARG, KCNJ11, TCF2/HNF1B, and WFS1 or HNF4A that is related to dysfunctional pancreatic b-cell secretion and GDM, suggesting new possibilities for the study of GDM $[21,22]$.

Some strands of scientific opinion suggest a possible role for epigenetic factors in the complex interplay between genes and the environment that are related to insulin resistance, T2D, and GDM mellitus [23]. These pathological conditions are associated with strong interactions between genetic susceptibility (usually a polygenic contribution) and environment influences over time, such as lifestyle and social influences (e.g., overfeeding, sedentarism, and obesity), or fetal surroundings (epidemiological studies suggest that the perinatal environment can predispose human offspring to developing obesity and T2D). These interactions may bring about the activation and/or deactivation of genes by epigenetic mechanisms, enabling adaptation to these various environmental situations [24].

1.2. Pathophysiology and Medical Complications. The pathogenesis of the most common type of GDM have been described similar to that of type 2 diabetes (T2D), with both pancreatic b-cell dysfunction and chronic insulin resistance playing crucial roles [25]. Pregnancy as an insulin resistant state may disclose pre-existing deficiency in insulin secretion or insulin sensitivity being present relative b-cell failure $[26,27]$.

Moreover, women with GDM after delivery often have an increased risk for metabolic syndrome, and they have been shown to express early markers of vascular dysfunction such as increased intimamedia thickness of carotid arteries [28]. Thus, pregnancy is a stress situation that may reveal predisposition to $\mathrm{T} 2 \mathrm{D}$ on women that provide early signs for prevention of essential chronic diseases [29]. High maternal adipose deposition [30] and low levels of exercise [31,32] also contribute to this state of relative insulin resistnce something that classically occurs in T2D. Other releasing factors, such as TNF $\alpha$ [33], leptin [34], human placental lactogen, cortisol, which is an insulin antagonist, estrogen, or progesterone have previously been found to affect the glucose-insulin balance [35].
There are outstanding medical complications that have been related to GDM for mother and also offspring. For mothers, GDM development have been related to overweight and obesity prior pregnancy [36] and also have been recognised as a sign of increased risk of developing type 2 diabetes (T2D) during life [37]. There are studies that have confirmed the risk of developing T2D in previously diagnosed GDM approximately $40 \%$ being followed up during ten year [38]. There is an increasing incidence of T2D (is highest in the first 5 years after pregnancy) which is frequently related with a substantial increase in BMI in women with GDM [39].

Congenital anomalies are not more common in patients with GDM but there is an increased incidence of stillbirth when glucose control is poor [40]. Organogenesis usually may start in the third week after fertilization, and it is almost completed by the 8th or 10th week of gestation so during the time most women are aware they are pregnant, substantial organogenesis has occurred. Maternal insulin does not cross the placental structures, and foetal beta islets are not developed to produce insulin until 12th week of gestation where early hyperglycemias can lead to congenital malformations and miscarriages, something that is two or three times more likely among patients with type 1 and type 2 diabetes than in healthy pregnancies [41].

This situation is also important because periconceptual hyperglycemia is known to be teratogenic and undiagnosed T2D might have a role in pregnancy outcome $[42,43]$. Congenital abnormalities (3\% incidence in total population) are not found more frequently in the offspring of patients with GDM when it is mostly diagnosed over 20th week of gestation [44] but abnormalities are more common in the offspring of patients with both T1D and T2D $[45,46]$.

Recent literature defines macrosomia as identical to large for gestational age (LGA), which is size $>90$ th percentile for gestational age [47] but this term is habitually used as birth weight over 4000 grams. When a fetus (over 12th week of gestation) is exposed to high levels of maternal glucose, it responds by secreting high levels of insulin in its circulation to control these hyperglycemias. This is a "double sword" mechanism where insulin that also has growth hormone properties develops a high tendency for foetal macrosomia and an increased rate of delivery complications [48]. Some risk for macrosomic and LGA infants deliveries may be found in the general population but is found higher in GDM, T2D, or postprandial hyperglycemic patients as well as high maternal prepregnancy weight or maternal age over $40[49,50]$.

Moreover, postpartum neonatal hypoglycemia may occur when neonates are no longer exposed to high levels of maternal glucose. At delivery, neonates continue producing elevated rates of insulin, but without high levels of maternal glucose that leads to a virtual neonatal hyperinsulinemia and subsequent hypoglycemias, requiring glucose infusion after delivery [51].

Finally, other important complications have been described in offspring of diabetic gestations with repercussions in future. Children who have been diagnosed LGA at birth and were exposed to an intrauterine environment of either diabetes or maternal obesity developed an increased 
risk of metabolic syndrome (MS) during childhood. This increased rate of obesity prevalence among children and adults may have implications for perpetuating the cycle of obesity, insulin resistance, and their consequences (GDM, T2DM, MS, and cardiovascular diseases) in subsequent generations [52-54].

\section{Epigenetic Regulation}

Epigenetics is currently known as a science that studies changes in gene activity that take place without a change in the nucleotide sequence. Epigenetic modifications are transmitted from one cell generation to the next (mitotic inheritance) and can also be transmitted down organismal generations (meiotic inheritance) [55]. Epigenetic modifications may be induced by the incidence of environmental factors that affect these biological systems, making them important pathogenic mechanisms in complex multifactorial diseases.

Epigenetic modifications include DNA methylation, histone modification, and those of the microRNA machinery. These mechanisms explain how cells with identical genomic information can differentiate into distinct cell types with different phenotypes [56]. Cytosine residues present in CG dinucleotides of gene promoters are targets for DNA methylation, which is associated with transcriptional silencing of these genes. This silencing can be caused by repressing transcription factor binding or by recruiting proteins that specifically bind to methylated CGs (methyl-CG-binding proteins, e.g., MeCP2), which can further recruit histone deacetyltransferases (HDACs) and corepressors.

The enzymes that lead to DNA methylation are methyltransferases (DNMTs), of which there are types: DNMT1, which copies the pattern of DNA methylation during replication (methylation maintenance), and DNMT3a and DNMT3b, which are responsible for de novo DNA methylation [57]. In contrast, processes that demethylate DNA are not well understood. In eukaryotic cells genomic DNA is bundled with particular proteins, known as histones, to produce chromatin. The basic structure of chromatin is the nucleosome, which consists of 147 base pairs of DNA wrapped around an octamer of histone proteins consisting of an $\mathrm{H} 3-\mathrm{H} 4$ tetramer flanked on either side by an H2A-H2B dimer. Even if the core histones are densely packed, histone modifying enzymes can modify their NH2-terminal tails by acetylation, methylation, phosphorylation, sumoylation, or ubiquitination [58]. These modifications determine the accessibility of the DNA to the transcription machinery as well as being essential for replication, recombination and chromosomal organization. HDACs and histone acetyl transferases (HATs), respectively, remove and add acetyl groups to lysine residues on histone tails [59]. Although the levels of HAT activity and histone acetylation are known to correlate with those of gene transcription, the exact mechanisms promoting transcription are not very clear [60].

Native lysine residues on histone tails bear a positive charge that can bind negatively charged DNA to form a condensed structure with low transcriptional activity. An early suggestion was that histone acetylation removes these positive charges, thereby relaxing chromatin structure and facilitating access to the DNA for the transcriptional machinery to initiate transcription [60]. However, different models have recently been proposed wherein multiple histone modifications act in combination to regulate transcription [61]. Histone methylation can result in either transcriptional activation or inactivation, depending on the degree of methylation and the particular arginine and/or lysine residues modified. Histone methyltransferases and histone demethylases mediate these processes as well [62].

2.1. A possible Role of Epigenetic Mechanisms in GDM. As we previously commented, pregnancy is a pathological condition that may indicate a predisposition to develop T2D in near future. Moreover, several studies point towards GDM and $\mathrm{T} 2 \mathrm{D}$ as different faces of the same disease at diverse stages of life [63]. High maternal adipose deposition or low levels of exercise contribute to insulin resistance in both pathologies [64-66] meanwhile b-cell dysfunction has also been recognized as an important factor to develop T2D and GDM [67]. In this case, sharing the same predisposing conditions and knowing that development of T2D is related to important epigenetic mechanisms [68], it may be consistent to identify the role of those epigenetic mechanisms in GDM pathogenesis.

In T2D, b-cell damage usually arises as a result of a combination of genetic susceptibility and acquired damage. Numerous genes have been associated with islet cell dysfunction in T2D, including some that encode for transcription factors, glucose metabolism proteins, and molecules of the insulin signaling pathways [69].

$\mathrm{Pdx}-1$ is a pancreatic homeobox transcription factor that regulates pancreas development and b-cell differentiation. A reduction in Pdx-1 expression in humans and animal models has been shown to cause T2D, while mutations in this gene also cause the monogenic form of diabetes (MODY 4) [70]. Also, Park et al. have recently associated intrauterine growth retardation, impaired b-cell function, and T2D with the silencing of $\mathrm{Pdx}-1$ by epigenetic mechanisms [71]. Previous works have related the increased risk of developing GDM with variants of MODY genes but further studies are necessary to establish the possible role of Pdx-1 in GDM [72].

Glucose is an important physiological fuel for the b-cell, initializing ATP production, insulin secretion, and proliferation. However, chronic hyperglycemia has severe adverse effects on b-cell function, including glucose desensitization, b-cell exhaustion and finally a lack of insulin secretion and insulin storage [73].

Increased oxidative stress found in obese and T2D patients, lead to decreased insulin gene transcription by decreasing Pdx1 [74]. The mechanisms by which ROS reduces b-cell mass and function are not completely understood, but ROS can alter DNA methylation. The changes in DNA methylation patterns have been shown to affect the expression of multiple genes [75, 76]. Histones, because they have abundant lysine residues, are also very susceptible to oxidative stress [77]. Several studies have identified epigenetic modifications in genes involved in the development of T2D, as we previously described for the Pdx-1 gene. 
Glucose transporters are involved in the transport of glucose in most cells. GLUT4 is a member of the facilitative glucose transporter (GLUT) family, characterized by preferential expression in muscle and adipose tissues, where it is responsible for insulin-stimulated glucose uptake. GLUT4 is essential for the maintenance of normal glucose homeostasis [78].

In patients with $\mathrm{T} 2 \mathrm{D}$, insulin resistance is a product of decreased insulin-stimulated skeletal muscle glycogen synthesis, which can mostly be attributed to decreased insulin-stimulated glucose transport (Glut 4) activity [79] and similar alterations have been observed in maternal skeletal muscle in GDM [80, 81]. Glut 4 expression is further regulated by the interaction of the transcription factor MEF2 (myocyte enhancer factor 2) with HDAC5 (histone deacetylase 5), which deacetylates histone tails at Glut 4, resulting in a condensed chromatin structure and subsequently reduced Glut 4 expression [82]. Moreover, the MEF2 isoforms are differentially regulated in muscle and adipose tissue during periods of insulin deficiency [83]. These mechanisms could also be involved in Glut 4 alteration in GDM.

Insulin secretion in pancreatic islets is dependent upon mitochondrial function and production of ATP. The transcriptional coactivator peroxisome proliferator-activated receptor gamma coactivator-1 alpha (protein PGC-1alpha; gene PPARGC1A) is a master regulator of mitochondrial genes, and its expression is weak and related to impaired oxidative phosphorylation in the muscle of patients with T2D [84]. DNA methylation of the PPARGC1A promoter is greater in the pancreatic islets of patients with T2D than in those of healthy controls, which correlates inversely with PPARGC1A expression in diabetic islets. This weaker PPARGC1A expression is correlated with impaired glucosestimulated insulin secretion, which is known to require ATP, and suggests that epigenetic mechanisms may regulate insulin secretion in human islets.

PPARGC1A is a coactivator of PPARG and PPARA and regulates genes involved in energy metabolism [85]. An alteration in peroxisome proliferator-activated receptors (PPARs) has been described in common complications of pregnancy, including GDM, intrauterine growth restriction (IUGR), and preeclampsia (PE) [86-88], which suggests the existence of a similar epigenetic control of the PPAR or PPARGC1A genes, as has been described for T2D.

2.2. Epigenetic Effects of GDM in Offspring. The epigenome is most vulnerable to dysregulation during those phases of life associated with higher rates of change for tissue development and growth, like embryogenesis, fetal, and neonatal life and puberty $[89,90]$.

Classical theories of disease development assumed that genetic susceptibility and unhealthy adult lifestyle give rise to insulin resistance and $\mathrm{T} 2 \mathrm{D}$, but observational studies showed a link between intrauterine growth retardation and subsequent development of T2D [91]. More recent theories based on a model of the developmental origins of health and disease $(\mathrm{DOHaD})$ proposed that part of the susceptibility to $\mathrm{T} 2 \mathrm{D}$ originates during intrauterine life as a result of altered environmental fetal programming, further amplified by subsequent rapid childhood growth. Fetal undernutrition (sometimes manifested as low birth weight) and postnatal overnutrition can both increase the risk of future diabetes [92]. This is also observed in animal models of intrauterine growth retardation caused by uteroplacental insufficiency, which limits the supply of critical substrates, nutrients, and hormones to the fetus. This abnormal metabolic intrauterine environment may affect the development of the fetus in humans by inducing changes in gene expression by epigenetic mechanisms of susceptible cells, leading to the development of diabetes in adulthood.

In the case of GDM, glucose travels freely from the mother to the fetus, but maternal insulin does not. Thus, maternal GDM exposes the fetus to higher concentrations of glucose than normal, forcing the fetus to increase its own insulin production [93]. GDM has serious, longterm consequences for both child and mother, including a predisposition to obesity, metabolic syndrome, and diabetes in later life [94]. The transgenerational persistence of the insulin resistant phenotype may be related to nutritionally induced epigenetic changes that influence the expression of key genes. The observed heritability of some epigenetic signatures in animal and human models suggests that the epigenotype can be transmitted to the next generation [95].

An adverse intrauterine milieu affects the development of the fetus by modifying expression in both pluripotential cells and terminally differentiated, poorly replicated cells and is associated with epigenetically induced downregulation of key genes controlling b-cell development, differentiation, and function [96-99].

\section{Conclusions}

Gestational diabetes is a growing health concern, especially in certain predisposed populations. Although traditionally deemed not as dangerous for the developing fetus as pregestational diabetes, recent findings indicate that GDM may have serious long-term consequences for both child and mother.

A conceptual developmental disease framework for GDM emerges from the findings reviewed here. Epigenetic mechanisms may control insulin resistance in mothers during pregnancy diagnosed with GDM but could also predispose offspring to developing T2D in later stages of life. An increased need for insulin by the fetus to deal with the high levels of glucose caused by GDM is an environmental circumstance that probably triggers epigenetic changes in that early stage of life, involving genes critical to pancreatic development and b-cell function, peripheral glucose uptake and insulin resistance. Understanding the role of developmental programming genes is crucial to our understanding of GDM and its consequences for the mother and child and it might stimulate the development of further epigenetic therapeutic agents as modern tools for treating this disease. 


\section{References}

[1] P. Marchetti, F. Dotta, D. Lauro, and F. Purrello, "An overview of pancreatic beta-cell defects in human type 2 diabetes: implications for treatment," Regulatory Peptides, vol. 146, no. 1-3, pp. 4-11, 2008.

[2] R. K. Campbell, "Fate of the beta-cell in the pathophysiology of type 2 diabetes," Journal of the American Pharmacists Association, vol. 49, pp. S10-S15, 2009.

[3] A. B. Gilmartin, S. H. Ural, and J. T. Repke, "Gestational diabetes mellitus," Reviews in Obstetrics and Gynecology, vol. 1, pp. 129-134, 2008.

[4] E. A. Reece, "The fetal and maternal consequences of gestational diabetes mellitus," J Matern Fetal Neonatal Med, vol. 23, no. 3, pp. 199-203, 2010.

[5] A. Ben-Haroush, Y. Yogev, and M. Hod, "Epidemiology of gestational diabetes mellitus and its association with type 2 diabetes," Diabetic Medicine, vol. 21, no. 2, pp. 103-113, 2004.

[6] K. Baptiste-Roberts, B. B. Barone, T. L. Gary et al., "Risk factors for type 2 diabetes among women with gestational diabetes: a systematic review," American Journal of Medicine, vol. 122, no. 3, pp. 207-214, 2009.

[7] American Diabetes Association, "Diagnosis and classification of diabetes mellitus," Diabetes Care, vol. 29, pp. S43-S48, 2006.

[8] P. White, "Pregnancy complicating diabetes," The American Journal of Medicine, vol. 7, no. 5, pp. 609-616, 1949.

[9] M. R. Torloni, A. P. Betrán, B. L. Horta et al., "Prepregnancy BMI and the risk of gestational diabetes: a systematic review of the literature with meta-analysis: diagnostic in obesity and complications," Obesity Reviews, vol. 10, no. 2, pp. 194-203, 2009.

[10] K. A. Toulis, D. G. Goulis, E. M. Kolibianakis, C. A. Venetis, B. C. Tarlatzis, and I. Papadimas, "Risk of gestational diabetes mellitus in women with polycystic ovary syndrome: a systematic review and a meta-analysis," Fertility and Sterility, vol. 92, no. 2, pp. 667-677, 2009.

[11] G. Tamás and Z. Kerényi, "Gestational diabetes: current aspects on pathogenesis and treatment," Experimental and Clinical Endocrinology and Diabetes, vol. 109, supplement 2, pp. S400-S411, 2001.

[12] "Proceedings of the 4th International Workshop-Conference on Gestational Diabetes Mellitus. Chicago, Illinois, USA. 1416 March 1997," Diabetes care, vol. 21, supplement 2, pp. B1B167, 1998.

[13] J. Kaprio, J. Tuomilehto, M. Koskenvuo et al., "Concordance for type 1 (insulin-dependent) and type 2 (non-insulindependent) diabetes mellitus in a population-based cohort of twins in Finland," Diabetologia, vol. 35, no. 11, pp. 1060-1067, 1992.

[14] M. Lehtovirta, K. H. Pietiläinen, E. Levälahti et al., "Evidence that BMI and type 2 diabetes share only a minor fraction of genetic variance: a follow-up study of 23,585 monozygotic and dizygotic twins from the Finnish Twin Cohort Study," Diabetologia, vol. 53, pp. 1314-1321, 2010.

[15] J. A. S. McLellan, B. A. Barrow, J. C. Levy et al., "Prevalence of diabetes mellitus and impaired glucose tolerance in parents of women with gestational diabetes," Diabetologia, vol. 38 , no. 6 , pp. 693-698, 1995.

[16] A. O. Martin, J. L. Simpson, C. Ober, and N. Freinkel, "Frequency of diabetes mellitus in mothers of probands with gestational diabetes: possible maternal influence on the predisposition to gestational diabetes," American Journal of Obstetrics and Gynecology, vol. 151, no. 4, pp. 471-475, 1985.
[17] R. Sladek, G. Rocheleau, J. Rung et al., "A genome-wide association study identifies novel risk loci for type 2 diabetes," Nature, vol. 445, no. 7130, pp. 881-885, 2007.

[18] L. J. Scott, K. L. Mohlke, L. L. Bonnycastle et al., "A genomewide association study of type 2 diabetes in finns detects multiple susceptibility variants," Science, vol. 316, no. 5829, pp. 1341-1345, 2007.

[19] J. Robitaille and A. M. Grant, "The genetics of gestational diabetes mellitus: evidence for relationship with type 2 diabetes mellitus," Genetics in Medicine, vol. 10, no. 4, pp. 240250, 2008.

[20] N. Freinkel, B. E. Metzger, R. L. Phelps et al., "Gestational diabetes mellitus: a syndrome with phenotypic and genotypic heterogeneity," Hormone and Metabolic Research, vol. 18, pp. 427-439, 1986.

[21] M. Ridderstråle and L. Groop, "Genetic dissection of type 2 diabetes," Molecular and Cellular Endocrinology, vol. 297, no. 1-2, pp. 10-17, 2009.

[22] R. M. Watanabe, A. H. Xiang, H. Allayee et al., "Variation in the P2-promoter region of hepatocyte nuclear factor$4 \alpha$ (HNF4A) is associated with $\beta$-cell function in Mexican American families of a proband with gestational diabetes," Diabetes, vol. 54, supplement 1, p. A28, 2005.

[23] C. Ling and L. Groop, "Epigenetics: a molecular link between environmental factors and type 2 diabetes," Diabetes, vol. 58, pp. 2718-2725, 2009.

[24] M. E. Symonds, S. P. Sebert, M. A. Hyatt, and H. Budge, "Nutritional programming of the metabolic syndrome," Nature Reviews Endocrinology, vol. 5, no. 11, pp. 604-610, 2009.

[25] M. E. Griffin, M. Coffey, H. Johnson et al., "Universal vs. risk factor-based screening for gestational diabetes mellitus: detection rates, gestation at diagnosis and outcome," Diabetic Medicine, vol. 17, no. 1, pp. 26-32, 2000.

[26] T. A. Buchanan, "Pancreatic B-cell defects in gestational diabetes: implications for the pathogenesis and prevention of type 2 diabetes," Journal of Clinical Endocrinology and Metabolism, vol. 86, no. 3, pp. 989-993, 2001.

[27] B. Persson, L. Edwall, U. Hanson, E. Nord, and M. Westgren, "Insulin sensitivity and insulin response in women with gestational diabetes mellitus," Hormone and Metabolic Research, vol. 29, no. 8, pp. 393-397, 1997.

[28] S. Bo, S. Valpreda, G. Menato et al., "Should we consider gestational diabetes a vascular risk factor?" Atherosclerosis, vol. 194, no. 2, pp. e72-e79, 2007.

[29] R. J. Kaaja and I. A. Greer, "Manifestations of chronic disease during pregnancy," Journal of the American Medical Association, vol. 294, no. 21, pp. 2751-2757, 2005.

[30] G. Boden, "Fuel metabolism in pregnancy and in gestational diabetes mellitus," Obstetrics and Gynecology Clinics of North America, vol. 23, no. 1, pp. 1-10, 1996.

[31] R. Iqbal, G. Rafique, S. Badruddin, R. Qureshi, R. Cue, and K. Gray-Donald, "Increased body fat percentage and physical inactivity are independent predictors of gestational diabetes mellitus in South Asian women," European Journal of Clinical Nutrition, vol. 61, no. 6, pp. 736-742, 2007.

[32] N. Oostdam, M. N. M. van Poppel, E. M. W. Eekhoff, M. G. A. J. Wouters, and W. van Mechelen, "Design of FitFor2 study: the effects of an exercise program on insulin sensitivity and plasma glucose levels in pregnant women at high risk for gestational diabetes," BMC Pregnancy and Childbirth, vol. 9, article 1, 2009. 
[33] J. P. Kirwan, S. Hauguel-De Mouzon, J. Lepercq et al., "TNF$\alpha$ is a predictor of insulin resistance in human pregnancy," Diabetes, vol. 51, no. 7, pp. 2207-2213, 2002.

[34] A. Kautzky-Willer, G. Pacini, A. Tura et al., "Increased plasma leptin in gestational diabetes," Diabetologia, vol. 44, no. 2, pp. 164-172, 2001.

[35] C. Kühl, "Etiology and pathogenesis of gestational diabetes," Diabetes Care, vol. 21, no. 2, pp. B19-B26, 1998.

[36] A. S. Morisset, A. St-Yves, J. Veillette, S. J. Weisnagel, A. Tchernof, and J. Robitaille, "Prevention of gestational diabetes mellitus: a review of studies on weight management," Diabetes Metab Res Rev, vol. 26, no. 1, pp. 17-25, 2010.

[37] A. Ben-Haroush, Y. Yogev, and M. Hod, "Epidemiology of gestational diabetes mellitus and its association with type 2 diabetes," Diabetic Medicine, vol. 21, no. 2, pp. 103-113, 2004.

[38] J. Lauenborg, T. Hansen, D. M. Jensen et al., "Increasing incidence of diabetes after gestational diabetes: a long-term follow-up in a Danish population," Diabetes Care, vol. 27, no. 5, pp. 1194-1199, 2004.

[39] C. Kim, K. M. Newton, and R. H. Knopp, "Gestational diabetes and the incidence of type 2 diabetes: a systematic review," Diabetes Care, vol. 25, no. 10, pp. 1862-1868, 2002.

[40] B. M. Rosenn, "Antenatal fetal testing in pregnancies complicated by gestational diabetes mellitus," Seminars in Perinatology, vol. 26, no. 3, pp. 210-214, 2002.

[41] J. L. Kitzmiller, T. A. Buchanan, S. Kjos, C. A. Combs, and R. E. Ratner, "Pre-conception care of diabetes, congenital malformations, and spontaneous abortions," Diabetes Care, vol. 19, no. 5, pp. 514-541, 1996.

[42] E. A. Ryan, "Pregnancy in diabetes," Medical Clinics of North America, vol. 82, no. 4, pp. 823-845, 1998.

[43] T. Cundy, G. Gamble, K. Townend, P. G. Henley, P. MacPherson, and A. B. Roberts, "Perinatal mortality in type 2 diabetes mellitus," Diabetic Medicine, vol. 17, no. 1, pp. 33-39, 2000.

[44] L. Kelly, L. Evans, and D. Messenger, "Controversies around gestational diabetes. Practical information for family doctors," Canadian Family Physician, vol. 51, pp. 688-695, 2005.

[45] V. M. Allen, B. A. Armson, R. D. Wilson et al., "Teratogenicity associated with pre-existing and gestational diabetes," Journal of Obstetrics and Gynaecology Canada, vol. 29, no. 11, pp. 927944, 2007.

[46] T. Farrell, L. Neale, and T. Cundy, "Congenital anomalies in the offspring of women with type 1, type 2 and gestational diabetes," Diabetic Medicine, vol. 19, no. 4, pp. 322-326, 2002.

[47] HAPO Study Cooperative Research Group, "The Hyperglycemia and Adverse Pregnancy Outcome (HAPO) study," The International Journal of Gynecology \& Obstetrics, vol. 78, no. 1, pp. 69-77, 2002.

[48] C. T. Witkop, D. Neale, L. M. Wilson, E. B. Bass, and W. K. Nicholson, "Active compared with expectant delivery management in women with gestational diabetes: a systematic review," Obstetrics and Gynecology, vol. 113, no. 1, pp. 206217, 2009.

[49] S. G. Gabbe and C. R. Graves, "Management of diabetes mellitus complicating pregnancy," Obstetrics and Gynecology, vol. 102, no. 4, pp. 857-868, 2003.

[50] M. C. Jolly, N. J. Sebire, J. P. Harris, L. Regan, and S. Robinson, "Risk factors for macrosomia and its clinical consequences: a study of 350,311 pregnancies," European Journal of Obstetrics Gynecology and Reproductive Biology, vol. 111, no. 1, pp. 9-14, 2003.
[51] B. Persson, "Neonatal glucose metabolism in offspring of mothers with varying degrees of hyperglycemia during pregnancy," Seminars in Fetal and Neonatal Medicine, vol. 14, no. 2, pp. 106-110, 2009.

[52] C. M. Boney, A. Verma, R. Tucker, and B. R. Vohr, "Metabolic syndrome in childhood: association with birth weight, maternal obesity, and gestational diabetes mellitus," Pediatrics, vol. 115, no. 3, pp. e290-e296, 2005.

[53] B. R. Vohr and C. M. Boney, "Gestational diabetes: the forerunner for the development of maternal and childhood obesity and metabolic syndrome?" Journal of Maternal-Fetal and Neonatal Medicine, vol. 21, no. 3, pp. 149-157, 2008.

[54] T. R. Moore, "Fetal exposure to gestational diabetes contributes to subsequent adult metabolic syndrome," American Journal of Obstetrics \& Gynecology, vol. 202, pp. 643-649, 2010.

[55] S. Kimmins and P. Sassone-Corsi, "Chromatin remodelling and epigenetic features of germ cells," Nature, vol. 434, no. 7033, pp. 583-589, 2005.

[56] A. Bird, "Perceptions of epigenetics," Nature, vol. 447, no. 7143, pp. 396-398, 2007.

[57] T. Clouaire and I. Stancheva, "Methyl-CpG binding proteins: specialized transcriptional repressors or structural components of chromatin?" Cellular and Molecular Life Sciences, vol. 65, no. 10, pp. 1509-1522, 2008.

[58] T. Kouzarides, "Chromatin modifications and their function," Cell, vol. 128, no. 4, pp. 693-705, 2007.

[59] M. Haberland, R. L. Montgomery, and E. N. Olson, "The many roles of histone deacetylases in development and physiology: implications for disease and therapy," Nature Reviews Genetics, vol. 10, no. 1, pp. 32-42, 2009.

[60] M. D. Shahbazian and M. Grunstein, "Functions of sitespecific histone acetylation and deacetylation," Annual Review of Biochemistry, vol. 76, pp. 75-100, 2007.

[61] Z. Wang, C. Zang, J. A. Rosenfeld et al., "Combinatorial patterns of histone acetylations and methylations in the human genome," Nature Genetics, vol. 40, no. 7, pp. 897-903, 2008.

[62] R. Marmorstein and R. C. Trievel, "Histone modifying enzymes: structures, mechanisms, and specificities," Biochimica et Biophysica Acta, vol. 1789, no. 1, pp. 58-68, 2009.

[63] R. Kaaja and T. Rönnemaa, "Gestational diabetes: pathogenesis and consequences to mother and offspring," Review of Diabetic Studies, vol. 5, no. 4, pp. 194-202, 2008.

[64] G. Boden, "Fuel metabolism in pregnancy and in gestational diabetes mellitus," Obstetrics and Gynecology Clinics of North America, vol. 23, no. 1, pp. 1-10, 1996.

[65] R. Iqbal, G. Rafique, S. Badruddin, R. Qureshi, R. Cue, and K. Gray-Donald, "Increased body fat percentage and physical inactivity are independent predictors of gestational diabetes mellitus in South Asian women," European Journal of Clinical Nutrition, vol. 61, no. 6, pp. 736-742, 2007.

[66] N. Oostdam, M. N. M. van Poppel, E. M. W. Eekhoff, M. G. A. J. Wouters, and W. van Mechelen, "Design of FitFor2 study: the effects of an exercise program on insulin sensitivity and plasma glucose levels in pregnant women at high risk for gestational diabetes," BMC Pregnancy and Childbirth, vol. 9, article 1, 2009.

[67] T. A. Buchanan and A. H. Xiang, "Gestational diabetes mellitus," Journal of Clinical Investigation, vol. 115, no. 3, pp. 485-491, 2005.

[68] R. A. Simmons, "Developmental origins of diabetes: the role of epigenetic mechanisms," Current Opinion in Endocrinology, Diabetes and Obesity, vol. 14, no. 1, pp. 13-16, 2007. 
[69] K. J. Chang-Chen, R. Mullur, and E. Bernal-Mizrachi, " $\beta$-cell failure as a complication of diabetes," Reviews in Endocrine and Metabolic Disorders, vol. 9, no. 4, pp. 329-343, 2008.

[70] B. R. Gauthier, A. Wiederkehr, M. Baquié et al., "PDX1 deficiency causes mitochondrial dysfunction and defective insulin secretion through TFAM suppression," Cell Metabolism, vol. 10, no. 2, pp. 110-118, 2009.

[71] J. H. Park, D. A. Stoffers, R. D. Nicholls, and R. A. Simmons, "Development of type 2 diabetes following intrauterine growth retardation in rats is associated with progressive epigenetic silencing of Pdx1," Journal of Clinical Investigation, vol. 118 , no. 6 , pp. 2316-2324, 2008.

[72] N. Shaat, E. Karlsson, Å. Lernmark et al., "Common variants in MODY genes increase the risk of gestational diabetes mellitus," Diabetologia, vol. 49, no. 7, pp. 1545-1551, 2006.

[73] N. Kaiser, G. Leibowitz, and R. Nesher, "Glucotoxicity and $\beta$-cell failure in type 2 diabetes mellitus," Journal of Pediatric Endocrinology and Metabolism, vol. 16, no. 1, pp. 5-22, 2003.

[74] H. Kaneto, D. Kawamori, T.-A. Matsuoka, Y. Kajimoto, and Y. Yamasaki, "Oxidative stress and pancreatic $\beta$-cell dysfunction," American Journal of Therapeutics, vol. 12, no. 6, pp. 529-533, 2005.

[75] R. Franco, O. Schoneveld, A. G. Georgakilas, and M. I. Panayiotidis, "Oxidative stress, DNA methylation and carcinogenesis," Cancer Letters, vol. 266, no. 1, pp. 6-11, 2008.

[76] M. J. Hitchler and F. E. Domann, "An epigenetic perspective on the free radical theory of development," Free Radical Biology and Medicine, vol. 43, no. 7, pp. 1023-1036, 2007.

[77] I. Rahman, J. Marwick, and P. Kirkham, "Redox modulation of chromatin remodeling: impact on histone acetylation and deacetylation, NF- $\kappa \mathrm{B}$ and pro-inflammatory gene expression," Biochemical Pharmacology, vol. 68, no. 6, pp. 1255-1267, 2004.

[78] M. Ishiki and A. Klip, "Minireview: recent developments in the regulation of glucose transporter-4 traffic: new signals, locations, and partners," Endocrinology, vol. 146, no. 12, pp. 5071-5078, 2005.

[79] K. F. Petersen and G. I. Shulman, "Etiology of insulin resistance," American Journal of Medicine, vol. 119, supplement 1, pp. S10-S16, 2006.

[80] M. Colomiere, M. Permezel, and M. Lappas, "Diabetes and obesity during pregnancy alter insulin signalling and glucose transporter expression in maternal skeletal muscle and subcutaneous adipose tissue," Journal of Molecular Endocrinology, vol. 44, pp. 213-223, 2010.

[81] M. Colomiere, M. Permezel, C. Riley, G. Desoye, and M. Lappas, "Defective insulin signaling in placenta from pregnancies complicated by gestational diabetes mellitus," European Journal of Endocrinology, vol. 160, no. 4, pp. 567-578, 2009.

[82] S. L. McGee and M. Hargreaves, "Exercise and skeletal muscle glucose transporter 4 expression: molecular mechanisms," Clinical and Experimental Pharmacology and Physiology, vol. 33, no. 4, pp. 395-399, 2006.

[83] S. Mora, C. Yang, J. W. Ryder, D. Boeglin, and J. E. Pessin, "The MEF2A and MEF2D isoforms are differentially regulated in muscle and adipose tissue during states of insulin deficiency," Endocrinology, vol. 142, no. 5, pp. 1999-2004, 2001.

[84] C. Ling, S. Del Guerra, R. Lupi et al., "Epigenetic regulation of PPARGC1A in human type 2 diabetic islets and effect on insulin secretion," Diabetologia, vol. 51, no. 4, pp. 615-622, 2008.

[85] B. N. Finck and D. P. Kelly, "PGC-1 coactivators: inducible regulators of energy metabolism in health and disease," Journal of Clinical Investigation, vol. 116, no. 3, pp. 615-622, 2006.
[86] S. Holdsworth-Carson, R. Lim, A. Mitton et al., "Peroxisome proliferator-activated receptors are altered in pathologies of the human placenta: gestational diabetes mellitus, intrauterine growth restriction and preeclampsia," Placenta, vol. 31, pp. 222-229, 2010.

[87] F. Wieser, L. Waite, C. Depoix, and R. N. Taylor, "PPAR action in human placental development and pregnancy and its complications," PPAR Research, vol. 2008, Article ID 527048, 2008.

[88] C. Giaginis, E. Spanopoulou, and S. Theocharis, "PPAR- $\gamma$ signaling pathway in placental development and function: a potential therapeutic target in the treatment of gestational diseases," Expert Opinion on Therapeutic Targets, vol. 12, no. 8, pp. 1049-1063, 2008.

[89] R. L. Jirtle and M. K. Skinner, "Environmental epigenomics and disease susceptibility," Nature Reviews Genetics, vol. 8, no. 4, pp. 253-262, 2007.

[90] W. S. Cutfield, P. L. Hofman, M. Mitchell, and I. M. Morison, "Could epigenetics play a role in the developmental origins of health and disease?" Pediatric Research, vol. 61, no. 5, pp. 68R75R, 2007.

[91] J. W. Rich-Edwards, G. A. Colditz, M. J. Stampfer et al., "Birthweight and the risk for type 2 diabetes mellitus in adult women," Annals of Internal Medicine, vol. 130, no. 4, pp. 278284, 1999.

[92] C. S. Yajnik and U. S. Deshmukh, "Maternal nutrition, intrauterine programming and consequential risks in the offspring," Reviews in Endocrine and Metabolic Disorders, vol. 9, no. 3, pp. 203-211, 2008.

[93] N. Weintrob, M. Karp, and M. Hod, "Short- and long-range complications in offspring of diabetic mothers," Journal of Diabetes and Its Complications, vol. 10, no. 5, pp. 294-301, 1996.

[94] E. A. Reece, G. Leguizamón, and A. Wiznitzer, "Gestational diabetes: the need for a common ground," The Lancet, vol. 373, no. 9677, pp. 1789-1797, 2009.

[95] M. F. Fraga, "Genetic and epigenetic regulation of aging," Current Opinion in Immunology, vol. 21, no. 4, pp. 446-453, 2009.

[96] P. Poulsen, M. Esteller, A. Vaag, and M. F. Fraga, "The epigenetic basis of twin discordance in age-related diseases," Pediatric Research, vol. 61, no. 5, pp. 38R-42R, 2007.

[97] S. E. Pinney and R. A. Simmons, "Epigenetic mechanisms in the development of type 2 diabetes," Trends in Endocrinology \& Metabolism, vol. 21, pp. 223-229, 2010.

[98] R. A. Simmons, "Role of metabolic programming in the pathogenesis of $\beta$-cell failure in postnatal life," Reviews in Endocrine and Metabolic Disorders, vol. 8, no. 2, pp. 95-104, 2007.

[99] N. Raychaudhuri, S. Raychaudhuri, M. Thamotharan, and S. U. Devaskar, "Histone code modifications repress glucose transporter 4 expression in the intrauterine growth-restricted offspring," Journal of Biological Chemistry, vol. 283, no. 20, pp. 13611-13626, 2008. 


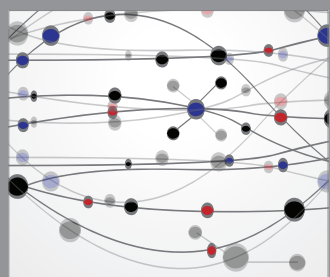

The Scientific World Journal
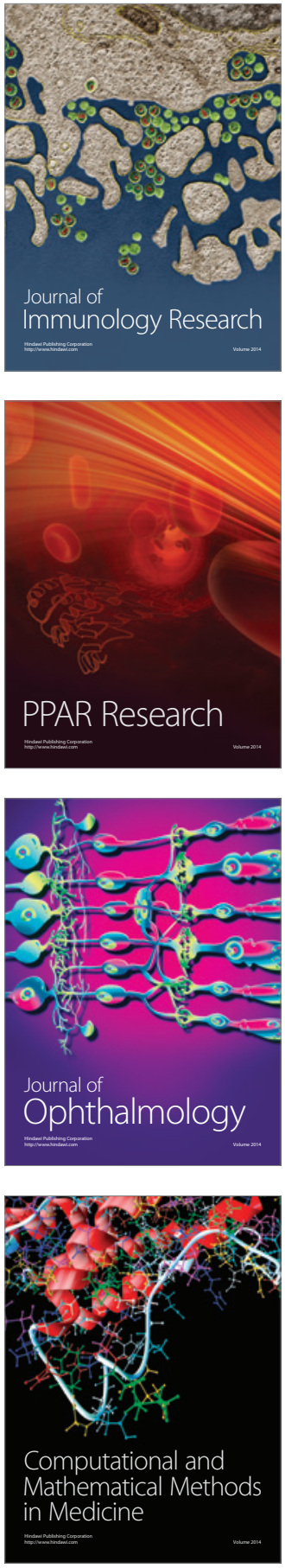

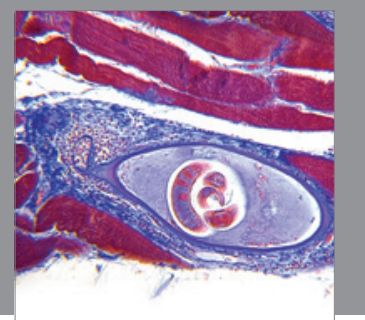

Gastroenterology

Research and Practice
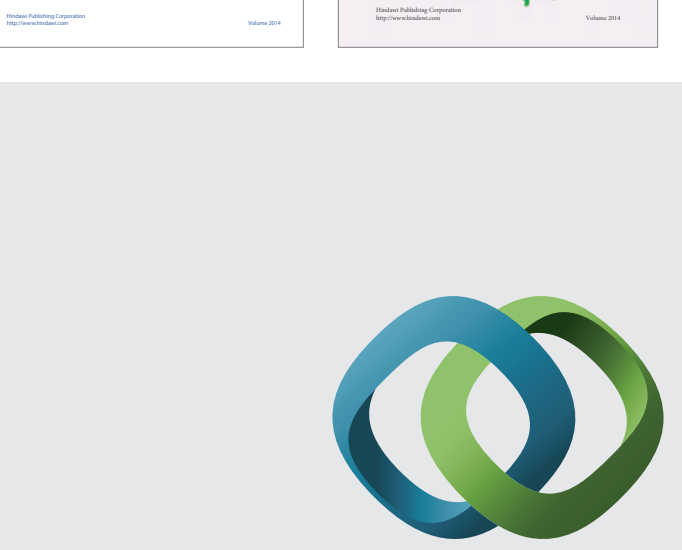

\section{Hindawi}

Submit your manuscripts at

http://www.hindawi.com
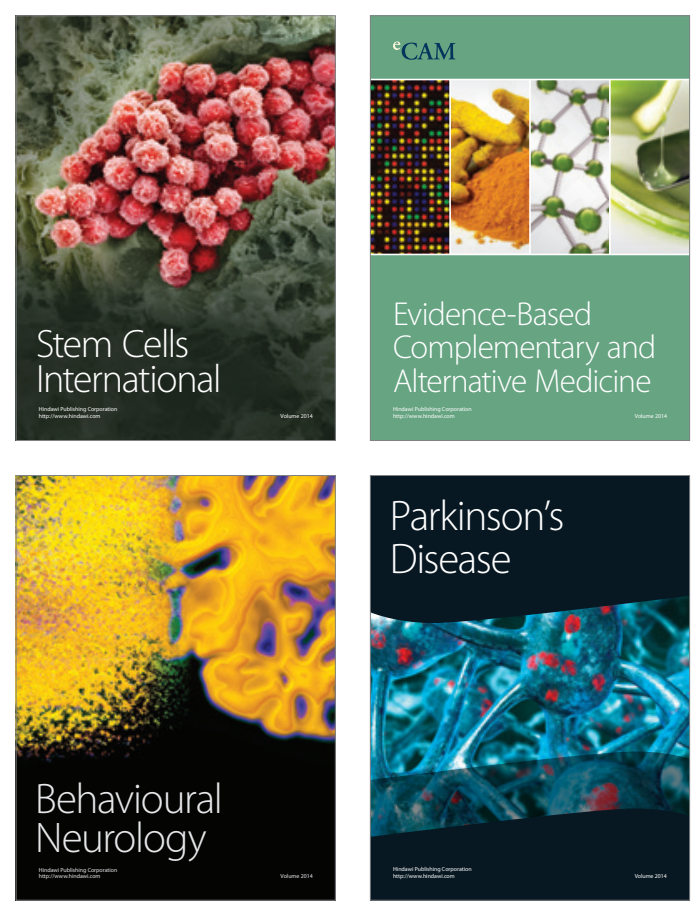

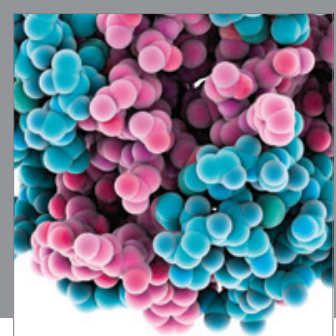

Journal of
Diabetes Research

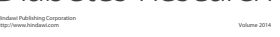

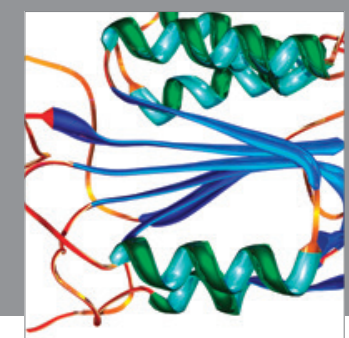

Disease Markers
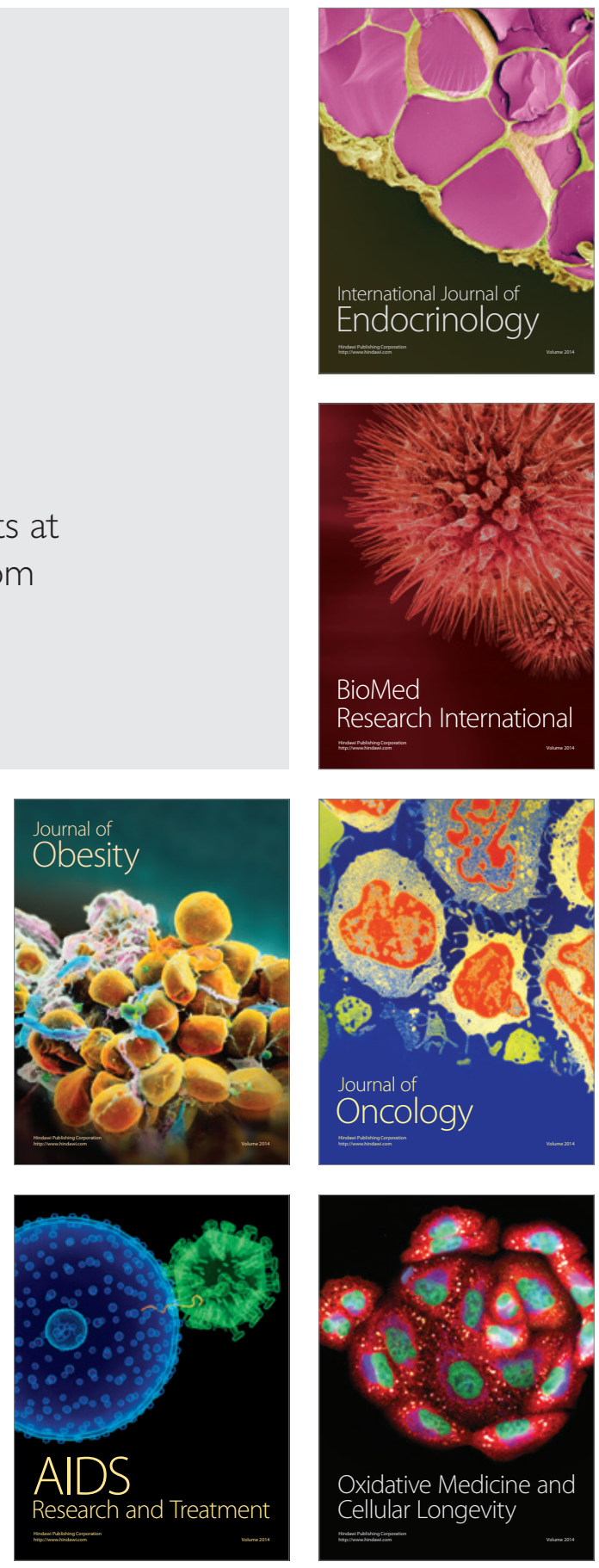